\title{
Progress on Antiangiogenic Therapy for Patients with Malignant Glioma
}

\author{
Manmeet S. Ahluwalia ${ }^{1,2}$ and Candece L. Gladson ${ }^{1,3}$ \\ ${ }^{1}$ Brain Tumor Neuro-Oncology Center, Neurological Institute, Cleveland Clinic, Cleveland, Ohio 44195, USA \\ ${ }^{2}$ Department of Solid Tumor Oncology, Taussig Cancer Institute, Cleveland Clinic, Cleveland, Ohio 44195, USA \\ ${ }^{3}$ Department of Cancer Biology, Lerner Research Institute, Cleveland Clinic, Cleveland, Ohio 44195, USA
}

Correspondence should be addressed to Candece L. Gladson, gladsoc@ccf.org

Received 21 November 2009; Revised 25 January 2010; Accepted 11 February 2010

Academic Editor: Arkadiusz Dudek

Copyright ( 2010 M. S. Ahluwalia and C. L. Gladson. This is an open access article distributed under the Creative Commons Attribution License, which permits unrestricted use, distribution, and reproduction in any medium, provided the original work is properly cited.

\begin{abstract}
Glioblastoma (GBM) is the most common primary brain tumor occurring in America. Despite recent advances in therapeutics, the prognosis for patients with newly diagnosed GBM remains dismal. As these tumors characteristically show evidence of angiogenesis (neovascularization) there has been great interest in developing anti-angiogenic therapeutic strategies for the treatment of patients with this disease and some anti-angiogenic agents have now been used for the treatment of patients with malignant glioma tumors. Although the results of these clinical trials are promising in that they indicate an initial therapeutic response, the anti-angiogenic therapies tested to date have not changed the overall survival of patients with malignant glioma tumors. This is due, in large part, to the development of resistance to these therapies. Ongoing research into key features of the neovasculature in malignant glioma tumors, as well as the general angiogenesis process, is suggesting additional molecules that may be targeted and an improved response when both the neovasculature and the tumor cells are targeted. Prevention of the development of resistance may require the development of anti-angiogenic strategies that induce apoptosis or cell death of the neovasculature, as well as an improved understanding of the potential roles of circulating endothelial progenitor cells and vascular co-option by tumor cells, in the development of resistance.
\end{abstract}

\section{Introduction}

Malignant gliomas include WHO grade IV gliomas, also known as glioblastomas (GBM), and WHO grade III gliomas referred to as anaplastic gliomas (AG) (anaplastic astrocytoma, anaplastic oligodendroglioma, and anaplastic oligoastrocytoma). GBM is the most common primary brain tumor occurring in the United States of America; approximately 10,000 new cases are diagnosed each year $[1,2]$. In this review, we will focus on the status of antiangiogenic therapy for GBM, as these tumors characteristically show evidence of angiogenesis (neovascularization) on histologic examination. Despite recent advances in therapeutics, the prognosis for patients with newly diagnosed GBM remains dismal; the median survival is 15 months when treated with the current standard of therapy, which is a combination of maximal surgical resection followed by concurrent chemoradiation and six months of adjuvant temozolomide [3]. Most patients with GBM develop tumor recurrence after the above therapy, and many centers are now treating these patients with bevacizumab (a monoclonal antibody to vascular endothelial growth factor (VEGF) that was recently approved by the FDA). Although clearly of benefit to some patients, the majority die within 6-9 months after initiation of anti-VEGF therapy [4-6]. Other antiangiogenic agents also have been examined in phase I or II clinical trials for patients with GBM, and promising results have emerged; however, a statistically significant increase in overall survival has not been reported to date. It is now becoming apparent that tumors also can act to enhance their vasculature through other mechanisms such as "co-option" of the existing vasculature. The contribution of these processes to tumor vascularization and their potential effects on anti-angiogenic therapies is an emerging field of great interest. 


\section{The Biology of Brain Tumor Vascularization}

GBMs are among the most vascular tumors known and hence the tumor-associated vasculature is an attractive therapeutic target [7]. It is now well established that tumors can promote the formation of new vessels through the process of angiogenesis. It is thought that when a tumor reaches a certain size, the requirements for oxygen and nutrients lead to the growth of new blood vessels $[8,9]$. The neovasculature that is formed in GBM never completely matures; however, this leads to an atypical vasculature that is constantly undergoing remodeling. There also is evidence to suggest that prior to the triggering of the process of formation of new vessels, tumor cells can obtain the necessary nutrients and oxygen by "co-opting" existing blood vessels [10]. This process appears to occur in very small tumors and appears to be dependent on the microenvironment in the specific organ and perhaps on the tumor type. In transplanted C6 rat gliomas in the rat brain co-option of existing blood vessels by tumor cells occurred initially when the tumors were several $\mathrm{mm}$ in diameter, and this was followed by vascular regression and ultimately by the development of a neovasculature [10]. Moreover, the process of vasculogenic mimicry [11], in which tumor cells function as blood vessel lining cells, may contribute to the blood supply in malignant tumors. Most of the research concerning tumor vasculature has focused on the mechanisms that promote the formation of new blood vessels through the process of angiogenesis and it is these mechanisms that have been targeted in the development of antiangiogenic therapies. Currently, relatively little is known concerning the mechanisms underlying co-option of blood vessels and vasculogenic mimicry, the effects of anti-angiogenic therapies on these processes, or the role of these processes in the activity of, or resistance to, the antiangiogenic therapies that have been developed.

\subsection{Angiogenic Growth Factors: Their Receptors and Function.} The signaling of VEGF, a proangiogenic growth factor, is important for GBM angiogenesis and involves paracrine interactions between the glioma cells, and the inflammatory cells that secrete VEGF, and the tumor-associated endothelial cells (EC) that express receptors for VEGF (VEGFR) [9]. The VEGF gene family is composed of five members: VEGFA, VEGF-B, VEGF-C, VEGF-D, and the placental-derived growth factor (PlGF) [10-12]. Of these, family members VEGF-A, VEGF-B, and PIGF are involved in vascular angiogenesis, whereas VEGF-C and -D regulate lymphatic angiogenesis [9]. VEGF-A was originally discovered as a factor that induces vascular permeability, and has since been shown to be an important EC mitogen [13, 14]. It belongs to the platelet-derived growth factor (PDGF) superfamily and is located on chromosome 6 [15]. Once secreted by the tumor cells, stromal cells or ECs, VEGF can be tethered in the extracellular matrix (ECM) due to an association with proteoglycans or glycosaminoglycans $[16,17]$.

The main receptors for VEGF-A are VEGFR1 and VEGFR2 [15]. These receptors are upregulated on the ECs in GBM as compared to the ECs of normal brain [18]. VEGFR2 is a major mediator of the mitogenic and angiogenic effects of VEGF through its activation of the phosphatidyl inositol 3-kinase (PI3K)/protein kinase B (AKT) and RAF-MAPK kinase-(MEK-) extracellular signal-regulated (ERK) MAP kinase pathways [15].

Basic fibroblast growth factor (bFGF) is another proangiogenic growth factor that is upregulated in GBM, in which it is expressed focally by tumor cells and also is expressed by the vasculature $[19,20]$. The receptors for bFGF include FGFR1, FGFR2, and FGFR4. FGFR1 is upregulated in GBM and is expressed by both the tumor cells and the tumor ECs. FGFR4 is expressed only by the tumor cells, and FGFR2 is not expressed in the tumors but it is expressed in the normal brain $[21,22]$. As is the case for VEGF, once secreted by the tumor cells, stromal cells or ECs, bFGF can be tethered in the ECM due to an association with proteoglycans or glycosaminoglycans $[16,17]$. Binding of bFGF to its receptor results in activation of the protein kinase $\mathrm{C} \alpha$ ( $\mathrm{PKC} \alpha$ ) pathway $[23,24]$ and the ERK pathway $[23,25]$.

In addition to VEGF and bFGF, several other proangiogenic molecules have been implicated in the initiation or amplification of angiogenesis in GBM including stem cell factor (SCF) and interleukin-8 (IL-8), hepatocyte growth factor and urokinase [26-30]. SCF mediates its signals through activation of the c-KIT receptor and may be of particular interest in GBM as its overexpression is associated with a shorter survival in patients with malignant glioma [31]. IL-8 is a chemokine that is synthesized by macrophages, ECs (where it is stored in the Weibel-Palade bodies), and other cell types (such as epithelial cells) [32, 33]. IL-8 is released from macrophages as a result of a host inflammatory response and activates ECs through the chemokine- 1 and 2 receptors (CXCR1 and CXCR2) [34].

Finally, in normal blood vessels, angiopoietin-1 (Ang1 ) is expressed by pericytes, binds the Tie2 tyrosine kinase receptor expressed on the associated EC and signals for survival and stabilization of the blood vessel $[35,36]$. In GBM there is increased expression of both Ang- 1 and its antagonist angiopoietin-2 (Ang-2); Ang-2 is expressed by the ECs, whereas Ang-1 is expressed by the tumor cells and is not expressed by the tumor blood vessels [37]. This has led investigators to speculate that Ang-2 may have a proangiogenic function in the neovasculature of tumors. Of note, Ang-2 expression has been implicated in the co-option process as described below [10].

\subsection{Proteolytic Degradation of the Basement Membrane,} Endothelial Cell Sprouting, and Tube Formation. Proteolytic degradation of the EC basement membrane by matrix metalloproteinases (MMPs) exposes the ECs to ECM proteins that can regulate angiogenesis and promote EC movement or sprouting $[11,28,31]$. These cell-ECM interactions occur through specific receptors and binding partners expressed on the EC surface, such as integrin cell adhesion receptors that recognize specific ECM molecules [9, 28, 34, 38, 39]. In addition, integrin receptors cooperate, collaborate, or crosstalk with growth factor receptors in a specific manner to enhance the signaling of both the integrin and the growth factor receptor. For example, in the chick chorioallantoic 
membrane model of angiogenesis, integrins $\alpha \mathrm{v} \beta 5$ and $\alpha \mathrm{v} \beta 3$, which are expressed on the EC, bind ligands in the chorioallantoic membrane and promote EC survival, proliferation, and sprouting (migration) by cooperating with VEGFR2 and FGFR, respectively [39]. At the same time, activation of the platelet-derived growth factor (PDGF) receptor signaling pathway recruits pericytes to the new EC tube, where they deposit ECM proteins that aid in the formation of a new EC basement membrane, inducing the expression of fibronectin and nidogen- 1 by the ECs [40-43]. Pericyte recruitment to the EC tube also promotes the upregulation of certain integrin receptors $(\alpha 6 \beta 1, \alpha 3 \beta 1, \alpha 1 \beta 1$, and $\alpha 5 \beta 1)$ on the ECs that mediate the interaction of the EC with fibronectin, nidogen-1, and laminin in the new basement membrane $[42,43]$.

Pericytes are necessary for stabilization of the new EC tube. The finding that EC tubes lacking pericyte coverage become dilated [42] suggests that pericyte coverage of the EC tube is necessary for maintaining the appropriate vessel diameter. This concept is consistent with the dilated and tortuous blood vessels that are observed on histologic examination of many GBM tumors and suggests that this may be associated with the reduced pericyte coverage of blood vessels observed in these tumors [36, 44].

Endothelial progenitor cells (EPCs) from the bone marrow may also contribute to the neovasculature. EPCs are mobilized from the bone marrow by the cytokine stromal-derived factor- $1 \alpha$ (SDF-1 $\alpha)$ [45] that is expressed by angiogenic vessels in GBM, SDF1 $\alpha$ binds to the G protein-coupled chemokine 4 receptor (CXCR4) expressed on circulating EPCs and also on tumor vessels [46]. A role for the SDF1 $\alpha /$ CXCR 4 signaling pathway in the development or maintenance of the GBM neovasculature is suggested by a report that demonstrated that the administration of a CXCR4 antagonist to an orthotopic xenograft mouse model of GBM inhibited tumor growth [47].

\subsection{Abnormalities in the Neovasculature of GBM and Hypoxia.} The failure of the GBM neovasculature to mature completely results in an atypical neovasculature that demonstrates excessive leakiness and lacks a normal blood brain barrier (BBB). Electron microscopic examination of the neovasculature in GBM has revealed that the tight junctions and adherens junctions (important contributors to the $\mathrm{BBB}$ ) are abnormal and that the actin filaments associated with the junctions are disorganized [48]. These changes likely decrease the osmotic gradient between the vasculature and interstitium, elevating the interstitial fluid pressure in the tumor [49]. This has certain important clinical implications. First, the elevated interstitial fluid pressure can compromise drug delivery to the GBM. Second, the abnormalities in the neovasculature may enhance tumor cell access to the vasculature and aid in tumor cell migration and invasion along the EC basement membrane to previously uninvolved brain tissue.

In addition, the neovasculature in GBM demonstrates prominent thrombosis, promoting local hypoxia within the tumor. This local hypoxia is exacerbated by the rapid growth of these tumors, which frequently results in an extensive necrotic core that further accentuates the hypoxic microenvironment. Hypoxia can promote tumor angiogenesis through activation of the transcription factor hypoxia-inducible factor $-1 \alpha$ (HIF- $1 \alpha$ ) which, in turn, enhances production of proangiogenic growth factors. Normally, the von HippelLindau (VHL) molecule inhibits the function of HIF- $1 \alpha$ but hypoxia destabilizes VHL causing it to dissociate from HIF$1 \alpha$. This results in HIF- $1 \alpha$ binding to the hypoxia response element (HRE) in the promoter of several proangiogenic factors (i.e., VEGF and SDF- $1 \alpha$ ) thereby initiating their transcription $[45,50]$. A second HIF family member, HIF$2 \alpha$, is also activated by hypoxia and likely plays a role in promoting tumor angiogenesis in GBM [51]. Li and colleagues [51] have recently demonstrated that HIF- $2 \alpha$ is preferentially expressed in glioma stem cells, in comparison to nonstem tumor cells and normal neural progenitors. Their work showed that HIF $2 \alpha$, not HIF $1 \alpha$, is selectively activated in glioma stem cells by hypoxia, inducing the expression of VEGF. In tumor specimens, HIF $2 \alpha$ colocalized with markers of cancer stem cells. Furthermore, targeting HIF in glioma stem cells inhibited self-renewal, proliferation, and survival in vitro, and attenuated the tumor initiation potential of glioma stem cells in mouse xenografts. Therefore, HIF $2 \alpha$ likely represents a promising new therapeutic target in patients with GBM [51].

2.4. Role of Cancer Stem Cells in Tumor Angiogenesis. In recent years, a minor population of cells has been identified in GBM and other malignant tumors that has characteristics of tumor-initiating cells. These cells have been referred to as cancer stem cells (CSCs) and in the case of GBM are referred to as glioma stem cells [52-54]. There is still some debate regarding the appropriate definition of CSCs, but an emerging consensus holds that these cells are capable of self-renewal, sustained proliferation, and initiating tumor formation when injected in very low numbers into an immunocompromised mouse host [55]. Of particular relevance to this review, a small but growing number of papers have suggested that CSCs promote angiogenesis in tumors. For example, Bao and colleagues (2006) demonstrated that conditioned media from glioma stem cells significantly promoted EC migration, proliferation, and tube formation as compared to conditioned media from nonstem glioma cells [56]. Consistent with this observation, Calabrese and colleagues (2007) showed that ECs interact closely with brain tumor stem cells in the perivascular location (this has been termed a vascular niche) and secrete factors that maintain these cells in a stem cell-like state [57]. Investigators have speculated that this vascular niche is an important target for therapeutic intervention, as disruption of the niche microenvironment can ablate the growth of CSCs and arrest tumor growth $[57,58]$. It should therefore be borne in mind that this is a potential mechanism by which anti-angiogenic drugs could inhibit brain tumor growth [57]. Most recently, Folkins and colleagues (2009) compared the angiogenesis in tumor xenografts from C6 glioma cells containing either a low or a high fraction of CSCs, and found that CSC-high xenograft tumors demonstrated an increased microvessel 
density and blood perfusion, as well as inducing greater mobilization and recruitment of bone marrow-derived EPCs to the tumors [59]. Also, the CSC-high C6 cultures and xenograft tumors expressed higher levels of VEGF and SDF1, and blocking of these proangiogenic factors resulted in a reduction in the growth of the tumors compared to that observed with CSC low C6 cells [59]. These data suggest that CSCs do contribute to tumor angiogenesis by promoting both local EC activity and systemic angiogenic processes that involve the recruitment of bone marrow-derived EPC in a VEGF-and SDF1-dependent manner [59].

2.5. Role of Bone Marrow-Derived Progenitor Cells in Tumor Angiogenesis. There is evidence that the adult bone marrow plays a significant role in endothelial and lymphatic neovessel formation that supports tumor growth and invasion $[60,61]$. As the brain lacks a lymphatic system, lymphatic neovessel formation is not relevant for GBM. The nonhematopoietic $\left(\mathrm{CD} 45^{-}\right)$bone marrow-derived population of cells that likely contribute to tumor angiogenesis, bone marrow-derived EPCs, may directly contribute to the EC layer by merging with the wall of a growing blood vessel and differentiating into ECs, thereby providing an alternative source of ECs [62]. The circulating EPCs originally reported by Asahara et al. (1997) (defined as CD $34^{+/}$VEGFR2 $^{+}$) were shown to be capable of differentiating into an EC phenotype that expressed EC markers in vitro, and to be capable of incorporating into neovessels at sites of ischemia [62]. Shaked and colleagues (2006) showed that administration of a vascular disrupting agent, such as combretastatin, or chemotherapeutic drugs, such as Paclitaxel or 5-fluorouracil, to a mouse model of cancer resulted in the recruitment of bone marrow-derived EPCs to the tumor as well as severe tumor necrosis [63]. Other studies have suggested that circulating EPCs may contribute to tumor neovascularization in mouse models of cancer [64].

It should be noted that the contribution of circulating EPCs to neoangiogenesis has been questioned and the markers that identify bone marrow-derived EPCs have been debated vigorously $[65,66]$. The reported level of incorporation of circulating EPCs into new blood vessels varies considerably and ranges in different studies from 5\% to $50 \%$ $[53,63,65,67]$. In addition, technical challenges exist in identifying vessel-incorporated bone marrow-derived EPCs. Most recently, Rafat and colleagues (2009) suggested that in 12 patients with GBM higher numbers of circulating EPCs appeared to correlate with a significantly higher tumor vessel density, as compared to patients with lower numbers of circulating EPCs [68]; however, this observation needs to be validated in a larger study.

Bone marrow-derived hematopoietic cells have also been reported to contribute to tumor angiogenesis and invasion. Unlike the circulating EPCs discussed above, these cells are $\mathrm{CD}_{4} 5^{+}$, and they include myeloid progenitor cells identified as $\mathrm{GR} 1^{+} \mathrm{CD} 11 \mathrm{~b}^{+}$in the mouse (in the human $\mathrm{CD}^{+}, \mathrm{CD}_{1} 4^{+}, \mathrm{CD} 19^{+}, \mathrm{CD}^{2} 7^{+}$and HLA-DR negative) [69], $\mathrm{CD} 1 \mathrm{~b}^{+} \mathrm{F} 4 / 80^{+}$tumor-associated macrophages (TAMs) [70], Tie2-expressing monocytes
[71], CXCR4 ${ }^{+}$VEGFR1 ${ }^{+}$hemangiocytes [72], bone marrowderived circulating cells that comprise a heterogeneous population of myeloid cells identified as $\mathrm{CD} 45^{+} \mathrm{CD} 11 \mathrm{~b}{ }^{+}$in the mouse and human [73], platelet-derived growth factor receptor $(\mathrm{PDGFR})^{+}$pericyte progenitors [74], and vascular endothelial-(VE-) cadherin ${ }^{+} \mathrm{CD}^{+} 5^{+}$leukocytes [75]. Supporting their potential importance in the response of the tumor to therapy, Shojaei and Ferrara reported that the recruitment of bone marrow-derived $\mathrm{GR}^{+}$myeloid cells resulted in a tumor that was refractory to treatment with inhibitors of VEGF [76]. In general, the above CD45 bone marrow-derived cells are not thought to incorporate into the EC layer of the new vasculature; rather, some of the above cells are thought to incorporate into the tumor neovasculature as perivascular cells where they function to promote angiogenesis through paracrine mechanisms, such as local secretion of VEGF [73].

\subsection{Co-Option of Existing Blood Vessels Occurs in Very Small} Tumors. As discussed above, there is evidence to suggest that in small tumors, in which the neovasculature has not developed, the tumor cells obtain the necessary nutrients and oxygen needed for growth by co-opting existing blood vessels [10]. Of note, in transplanted C6 rat gliomas in the rat brain co-option of existing blood vessels by tumor cells occurred initially when the tumors were several $\mathrm{mm}$ in diameter, and this was followed by vascular regression and ultimately by the development of a neovasculature [10]. The same study also showed co-option of existing blood vessels with the propagation of rat mammary cancer cells in the rat brain and with the metastasis of Lewis lung cancer cells to the lung after intravenous injection. In each of these models, Ang-2 expression was upregulated at the co-opted blood vessels, suggesting a role for Ang-2 signaling in the co-option process [10]. Vessel co-option has been observed in several other tumors, including melanoma, ovarian carcinoma, and Kaposi sarcoma (reviewed in [11]).

Another mechanism contributing to the blood supply in malignant tumors is vasculogenic mimicry [11]. In vasculogenic mimicry, tumor cells function as blood vessel lining cells and this has been described in several types of malignant tumors, including melanoma [11].

\section{Clinical Use of Antiangiogenic Agents}

3.1. VEGF Inhibitors. Bevacizumab is a monoclonal antibody directed toward VEGF that has become the prototype of antiangiogenic agents in clinical use for treatment of GBM (see Table 1). In a phase II clinical trial, 68 patients with recurrent malignant glioma ( $33 \mathrm{AG}$ and $35 \mathrm{GBM}$ ) were treated with bevacizumab and irinotecan in two cohorts (see Table 2). The combination therapy produced an impressive initial radiographic response rate of $57 \%$ for GBM and $61 \%$ for AG $[5,77]$. This compared favorably with the benchmark response rate for temozolomide therapy at the first tumor recurrence, 5\% for patients with recurrent GBM and 35\% for patients with recurrent AG [78-80]. With the combination of bevacizumab and irinotecan the progression-free survival 
TABLE 1: Examples of antiangiogenic agents in clinical trial for patients with high grade glioma.

\begin{tabular}{|c|c|c|}
\hline Drug & Type & Targets \\
\hline ABT-510 & Thrombospondin-1 mimetic peptide & CD36 receptor \\
\hline AMG 102 & Monoclonal antibody & $\mathrm{HGF} / \mathrm{SF}$ \\
\hline Aflibercept & Soluble decoy receptor & VEGF-A,B, PlGF \\
\hline Bevacizumab & Monoclonal antibody & VEGF-A \\
\hline Brivanib & Tyrosine kinase inhibitor & FGFR, VEGFR2 \\
\hline Cediranib & Tyrosine kinase inhibitor & VEGFR1-3, PDGFR $\beta$, c-Kit \\
\hline Cilengitide & RGD synthetic peptide & Integrins $\alpha \mathrm{v} \beta 3, \alpha \mathrm{v} \beta 5$ \\
\hline CT-322 & Fibronectin (adnectin)-based inhibitor & VEGFR1-3 \\
\hline Dasatinib & Tyrosine kinase inhibitor & PDGFR $\beta$, Src, BCR-ABL, c-Kit, EphA2 \\
\hline Imatinib & Tyrosine kinase inhibitor & PDGFR $\beta$, BCR-ABL, c-Kit \\
\hline Lenalidomide & Immunomodulatory and anti-inflammatory & FGF pathway \\
\hline Pazopanib (GW786034) & Tyrosine kinase inhibitor & VEGFR1-3, PDGFR $\beta$, c-Kit \\
\hline Sorafenib & Tyrosine kinase inhibitor & VEGFR2,3, BRAF, PDGFR $\beta$, c-Kit, Ras, p38 $\alpha$ \\
\hline Sunitinib & Tyrosine kinase inhibitor & VEGFR2, PDGFR $\beta$, Flt3, c-Kit \\
\hline Tandutinib (MLN518) & Tyrosine kinase inhibitor & PDGFR $\beta$, Flt3, c-Kit \\
\hline Vandetanib (ZD6474) & Tyrosine kinase inhibitor & VEGFR2, EGFR, RET \\
\hline Vatalanib (PTK787) & Tyrosine kinase inhibitor & VEGFR1-3, PDGFR $\beta$, c-Kit \\
\hline XL-184 & Tyrosine kinase inhibitor & VEGFR2, Met, RET, c-Kit, Flt3, Tie-2 \\
\hline
\end{tabular}

A more complete listing of anti-angiogenic agents in clinical trials for patients with high grade gliomas can be found at the National Institutes of Health website http://www.clinicaltrials.gov/ when searching for "glioma, brain cancer, glioblastoma, and angiogenesis".

at six months (PFS-6) was $43 \%$ for recurrent GBM patients and $59 \%$ for AG patients, and this was an improvement over the accepted PFS- 6 standard of $15 \%$ for GBM patients and $31 \%$ for AG patients treated with temozolomide $[79,80]$. Therapy with bevacizumab and irinotecan also resulted in neurological improvement and a reduction or discontinuation in the use of corticosteroid treatment in $31 \%$ of patients. The regimen was well tolerated; only one CNS hemorrhage was reported in 68 patients treated, eight patients were taken off of the study for thrombotic complications (four patients with pulmonary embolism (PE), two with deep vein thrombosis, one with thrombotic thrombocytopenic purpura, and one with thrombotic stroke), and two patients died (one with PE and one with a thrombotic stroke). Other side effects reported included, proteinuria, fatigue, and gastro-intestinal toxicity; these have been described with bevacizumab therapy for other types of cancer. Other prospective and retrospective studies have demonstrated initial radiographic response rates of between $35 \%$ and $50 \%$ with the combination of bevacizumab and cytotoxic chemotherapy [4, 81-83].

As irinotecan has limited activity as a single agent, a phase II randomized clinical trial was performed to evaluate the benefit of the addition of irinotecan to bevacizumab. In this clinical trial 167 patients with recurrent GBM received either bevacizumab alone or bevacizumab in combination with irinotecan; there was no statistically significant difference in the median overall survival (OS) for bevacizumab therapy alone (9.2 months) when compared to the combination bevacizumab and irinotecan therapy (8.7 months) [6]. A recent study evaluated the approach of bevacizumab monotherapy in patients with recurrent GBM followed by irinotecan combined with bevacizumab [84]. In this study, 17/48 patients (35\%) achieved an initial radiographic response and the PFS- 6 was reported to be $29 \%$. Addition of irinotecan to patients who progress on bevacizumab monotherapy failed to produce an objective radiographic response in any of the 19 patients [84]. Bevacizumab is presently being evaluated in the upfront setting with temozolomide and radiation in two randomized phase III trials sponsored by the Radiation Therapy Oncology Group and Hoffmann-La Roche [85, 86].

Other VEGF/VEGFR-targeted inhibitors include, Aflibercept, a soluble VEGF decoy or hybrid receptor that consists of portions of VEGFR-1 and -2 fused to an immunoglobulin G1 Fc region [87-89] and Cediranib (AZD2171), a pan-VEGFR tyrosine kinase inhibitor with activity against PDGFR and cKIT [90] (see Table 1).

\section{Multikinase Receptors Inhibitors (MTKI)}

A number of MTKIs have been studied in GBM patients (see Tables 1 and 2) including, Imatinib [95-99], Sorafenib [100-102], Sunitinib [103], Vandetanib (ZD6474) [104107], Vatalanib (PTK787) [91, 108-114], and XL184 [92, 115-117].

\section{Other Anti-Angiogenic Agents}

Other anti-angiogenic agents evaluated in GBM (see Tables 1 and 2) include, Thalidomide [93, 118-123], Lenalidomide [124, 125], Tamoxifen [126-129], Enzastaurin (LY317615) $[130,131]$, and the integrin inhibitor Cilengitide [94, 132, $133]$. 
TABLE 2: Selected clinical trials in patients with recurrent high grade glioma

\begin{tabular}{|c|c|c|c|c|c|}
\hline Agent & Phase & Diagnosis & $\begin{array}{l}\text { Number of patients } \\
\text { and Histology }\end{array}$ & Response Rate & PFS-6 \\
\hline $\operatorname{Bev}+\operatorname{Ir}[5,77]$ & II & Recurrent MG & $68(33 \mathrm{AG}, 35 \mathrm{GBM})$ & & $43 \% \mathrm{GBM}, 59 \% \mathrm{AG}$ \\
\hline Bev versus Bev + Ir [6] & II & Recurrent GBM & $\begin{array}{l}85 \text { GBM (Bev) Vs } \\
82 \text { GBM }(\mathrm{Bev}+\mathrm{Ir})\end{array}$ & $\begin{array}{l}\mathrm{RRR}=28 \%(\mathrm{Bev}), \mathrm{RRR}=37 \% \\
(\mathrm{Bev}+\mathrm{Ir})\end{array}$ & $\begin{array}{l}42 \%(\mathrm{Bev}) \text { versus } \\
50 \%(\mathrm{Bev}+\mathrm{Ir})\end{array}$ \\
\hline Aflibercept [89] & II & Recurrent MG & $48(16 \mathrm{AG}, 32 \mathrm{GBM})$ & $50 \%$ AG30\% GBM & \\
\hline Cediranib $[90]$ & II & Recurrent GBM & $16 \mathrm{GBM}$ & $56 \%$ & \\
\hline Vatalanib [91] & $\mathrm{I} / \mathrm{II}$ & Recurrent GBM & $55 \mathrm{GBM}$ & $\mathrm{PR}=4 \%, \mathrm{SD}=56 \%$ & \\
\hline XL184 [92] & II & Recurrent GBM & $26 \mathrm{GBM}$ & $\mathrm{PR}=38 \%$ & \\
\hline Thalidomide [93] & II & Recurrent MG & $39(14 \mathrm{AG}, 25 \mathrm{GBM})$ & $\mathrm{PR}=6 \%, \mathrm{MR}=6 \%, \mathrm{SD}=33 \%$ & \\
\hline Cilengitide [94] & II & Recurrent GBM & $81 \mathrm{GBM}$ & & $16 \%$ \\
\hline
\end{tabular}

Abbreviations: Bev: bevacizumab, Ir: Irinotecan, PFS-6: progression free survival at 6 months, MG: malignant glioma, GBM: glioblastoma, AG: anaplastic glioma (includes anaplastic astrocytoma, anaplastic oligodendrogioma and anaplastic oligoastrocytoma), RR: response rate, RRR: radiological response rate, PR: partial response, SD: stable disease, MR: minor response, TMZ: temozolomide, and XRT: radiation.

\section{Challenges in Evaluating the Response to Anti-Angiogenic Therapy with Imaging}

The Macdonald Criteria have been used since 1990 to define response or progression in clinical trials of malignant glioma [134]. The Macdonald Criteria, based on WHO Criteria, utilizes measurement of the largest cross-sectional area of tumor on contrast-enhanced CT or MRI scan. Malignant gliomas can be irregular in shape, include large necrotic cavities, or be partially or completely nonenhancing, creating difficulty in accurately measuring the largest cross-sectional area on contrast-enhanced CT or MRI scan. In addition, the interpreter needs to take into account concurrent corticosteroid use and changes in neurological function. Thus, response evaluation based on finding a difference in the largest cross-sectional area of tumor on contrast-enhanced CT or MRI is even more difficult with anti-angiogenic therapy.

Clinical trials with drugs that modify signal transduction through the VEGF signaling pathway (e.g., bevacizumab, and cediranib) can produce a rapid decrease in enhancement after initiation of therapy $[5,135]$, resulting in an apparent high response rate. Some of the changes observed on contrast-enhanced CT or MRI scan result from a rapid normalization of abnormally permeable blood vessels and are not due to an antitumor effect. Anti-angiogenic therapy likely decreases vascular permeability and restores at least in part the integrity of the $\mathrm{BBB}$, this leads to less contrast leakage from the vasculature. There is evidence that VEGF pathway-targeted anti-angiogenic drugs likely alter the image characteristics of enhancing tumor more effectively than of nonenhancing tumor. Hence the extent of reduction in contrast enhancement may not reflect true antitumor activity of the anti-angiogenic agent. Not infrequently, the radiographic image observed after anti-angiogenic therapy suggests a radiographic response that is more impressive than the clinical benefit derived from the therapy. The term "pseudoresponse" has been used to define the situation wherein the contrast-enhanced MRI suggests an antitumor effect that does not correlate with a true clinical benefit [136]. Therefore, treatment response based on radiographic images is probably not an optimal end point for clinical trials evaluating anti-angiogenic agents. The international Response Assessment in Neuro-Oncology (RANO) Working Group has developed new criteria for evaluating tumor response in malignant gliomas that take into account both enhancing and nonenhancing tumor (best visualized on T2 and fluid-attenuated inversion recovery (FLAIR) MRI sequences) images [136]. This working group proposes that increased T2-FLAIR signal likely reflects growing tumor, such as when it appears outside of the radiation field, it produces mass effect, or it involves the cortical ribbon, and when it occurs in the absence of other potential explanation.

\section{Resistance to Anti-Angiogenic Therapy}

Although the anti-angiogenic therapy of patients with malignant glioma has resulted in a small increase in the PFS-6, in general these agents have failed to produce a sustained clinical response. For example, patients with malignant glioma treated with a VEGF inhibitor have shown temporary improvements, seen as reduced edema on imaging or tumor stabilization on imaging; however, the tumors ultimately progress after a brief response. In patients with tumor progression during treatment with bevacizumab, the downhill clinical course is often rapid, and may be fueled by discontinuing the agent. In a retrospective analysis, patients with malignant glioma who were treated with a second line regimen containing bevacizumab after failure of treatment with an initial therapy combination of bevacizumab and a cytotoxic agent had a median PFS of only 37.5 days [137]. Shaked and colleagues showed that treatment withdrawal of a vascular disrupting agent, such as combrestatin, to a mouse model of cancer resulted in the development of an aggressive and angiogenic tumor [63]. Supporting the concept that malignant tumors ultimately develop resistance to therapy with a VEGF inhibitor, two recent studies (one of which 
included a xenograft mouse model of GBM) suggested that treatment with a VEGF inhibitor alters the natural history of the tumor and promotes a highly invasive and metastatic phenotype [138, 139].

The anti-angiogenic therapy failures described above are thought to be due to the development of resistance to anti-angiogenic therapy. Resistance to anti-angiogenic therapy has been broadly classified as either adaptive or intrinsic [140]. Animal models of malignant glioma and of other malignant tumors have shown that tumors adapt to treatment with angiogenesis inhibitors by upregulating, or acquiring, an alternate mechanism(s) to sustain tumor growth, which has been termed "adaptive evasive resistance". This can occur even when the specific target of the antiangiogenic agent remains successfully inhibited. Adaptive resistance along with intrinsic resistance is thought to be the reason for the progression of malignant tumors treated with anti-angiogenic therapy. In tumors that show an initial response to anti-angiogenic therapy, adaptive evasive resistance is thought to be the main mechanism for the development of resistance, that is, blockade of one proangiogenic growth factor can lead to upregulation of an alternate proangiogenic growth factor [141]. For example, in a study of GBM patients treated with the panVEGFR inhibitor cediranib (AZD 2171), blood levels of the proangiogenic factors bFGF and SDF $1 \alpha$ were noted to be higher in patients at the time of tumor progression or relapse as compared to the levels observed during the phase in which the patients showed a response to cediranib therapy [142].

Recruitment of vascular progenitor cells from the bone marrow may aid in the process of adaptive evasive resistance. Certain anti-angiogenic therapies can cause regression of tumor vessels resulting in hypoxia and lead to the recruitment of various bone marrow-derived progenitor cells. Bone marrow-derived progenitor cells (including both vascular progenitor cells and vascular modulatory cells) can be recruited through hypoxia-induced HIF1 $\alpha$ activation resulting in the expression of the downstream effector SDF1 $\alpha$ [45, 143-146]. GBM tumors with low HIF $1 \alpha$ levels contain fewer bone marrow-derived cells and exhibit lower levels of angiogenesis and tumor growth, as compared to GBM tumors with high HIF1 $\alpha$ levels [146]. This suggests that the recruitment of bone marrow-derived progenitor cells may constitute a mechanism for the development of adaptive evasive resistance to anti-angiogenic therapy.

One reason for the initial response to bevacizumab therapy reported for some patients with GBM may be that the GBM neovasculature typically contains a reduced density of pericyte coverage [36]. Pericytes are important constituents of blood vessels in general and of tumor blood vessels, they provide prosurvival signals to ECs. ECs are thought to induce pericyte recruitment, thereby promoting their own survival. Two of the best characterized prosurvival signals for ECs are VEGF and the signals derived from pericyte association with ECs [36]. Tumor vessels lacking adequate pericyte coverage are more vulnerable to VEGF inhibition as they lack the pro-survival signal from pericytes [147]. Blood vessels covered with the normal density of pericytes probably survive therapy with a VEGF inhibitor as the pericytes can signal for EC survival or quiescence $[148,149]$.

Finally, the possibility of the development of an alternative mechanism, such as co-option, for tumor cells to acquire oxygen and nutrients must be considered in terms of resistance. Notably, in an orthotopic mouse model of GBM treated with a VEGFR selective kinase inhibitor or with a multitarget VEGFR kinase inhibitor, tumor progression (growth) ultimately occurred that was highly invasive. Perivascular tumor invasion similar to tumor co-option of blood vessels was observed at autopsy. Moreover, two other recent studies have suggested that tumor co-option of pre-existing blood vessels can support a more invasive tumor cell phenotype and tumor growth after VEGF- or VEGFR2-targeted therapy [150, 151]. As Ang-2 signaling has been implicated in mediating blood vessel co-option in the untreated early C6 rat glioma model of malignant glioma [10], human GBM tumors were immunostained for Ang-1 and Ang-2 and it was reported that Ang-2 expression was upregulated at tumor co-opted blood vessels. Whether the co-opted blood vessels that were observed post anti-angiogenic therapy also showed upregulation of Ang-2 remains to be determined.

The second mechanism of resistance to anti-angiogenic therapy that has been suggested is an intrinsic or inherent resistance [140]. This concept stems from the observation that a minority of patients do not appear to respond to antiangiogenic therapy. It has been suggested that this may be due to the pre-existing activation of multiple proangiogenic signaling pathways or a pre-existing inflammatory cell infiltrate that provides a source of tumor VEGF resulting in vascular protection [140].

\section{The Blood-Brain Barrier (BBB) and the Challenges of Drug Delivery}

Drug concentrations within the central nervous system are dependent on multiple factors that include, the permeability of the agent across the BBB, the extent to which it is actively transported out of the brain, and the volume of distribution in the brain parenchyma [152]. The BBB is an anatomicphysiologic barrier that is formed by multiple components, including tight junctions between endothelial cells, pericytes, and the astrocytic foot processes. This barrier selectively allows entry of some substances, such as glucose, lipidsoluble molecules, and oxygen, while preventing entry of other substances. It is important to understand that although the BBB may be disrupted in some areas of a GBM, a substantial proportion of glioma cells can be located in areas with an intact BBB. The magnitude of tumor vascular permeability varies within these tumors, with the greatest permeability being found in the tumor core and a relatively intact $\mathrm{BBB}$ at the proliferating tumor edge. The presence of an intact $\mathrm{BBB}$ in some areas of the tumor and the presence of a partially functional $\mathrm{BBB}$ in other areas of the tumor can prevent the effective delivery of active therapeutic compounds. 
The BBB expresses high levels of drug efflux pumps such as $\mathrm{P}$-glycoprotein (P-gp), breast cancer-resistance protein (BCRP), and other multiple drug resistance proteins (MRPs) that actively remove chemotherapeutic drugs from the brain [153]. Efflux transport systems such as by P-gp and the MRPs at the brain capillary ECs may play a role in limiting the passage of therapeutic agents across the BBB [154]. For example, the brain distribution of the tyrosine kinase inhibitor imatinib is reduced by active efflux via the Pglycoprotein [155]. The BCRP drug efflux transport pump is expressed in a number of normal tissues, in addition to the BBB [156]. Modulation of drug transporters represents a new potential strategy to improve efficacy of targeted agents. Anti-angiogenic agents such bevacizumab that mainly target the $\mathrm{EC}$ on the luminal side of the vessel may not depend on the ability to cross the BBB; however, this remains a concern for tyrosine kinase inhibitors like imatinib.

\section{Biomarkers of Angiogenesis}

Currently, there are no validated biomarkers to monitor the progress or response to anti-angiogenic therapy in patients with malignant glioma or other cancers [157]. Two promising biomarkers for assessment of angiogenesis in malignant tumors are the number of circulating endothelial cells (CECs) and the number of circulating endothelial progenitor cells (EPCs). A growing body of literature suggests that the number of CECs and circulating EPCs is significantly elevated in patients with different types of cancer [65]. Furthermore, in a small number of preclinical animal studies successful antitumor response to anti-angiogenic therapy was correlated with changes in the number of CECs and circulating EPCs [158]. Rafat and colleagues have evaluated the number of circulating EPCs in the blood of patients with malignant glioma, and reported that they were higher in patients with GBM as compared to healthy volunteers [68]. Higher tumor blood vessel densities were noted in the patients with GBM having higher numbers of circulating EPCs as compared to those patients with lower numbers of circulating EPCs [68]. This supports the further evaluation of circulating EPCs as a novel biomarker for the assessment of angiogenesis and for the assessment of the response to antiangiogenic therapy in patients with GBM.

Measurement of VEGF plasma levels may not be a generally useful biomarker of tumor angiogenesis. For example, baseline plasma VEGF levels are not correlated with survival outcome for patients with metastatic colorectal cancer or for patients with metastatic nonsmall cell lung cancer $[159,160]$. As expected, the plasma level of VEGF in patients with GBM and brain metastases is elevated as compared to normal healthy volunteers. In patients with metastatic breast cancer higher plasma levels of VEGF were associated with shorter time of progression [161]. Thus, additional studies need to be performed to determine whether the measurement of plasma VEGF levels is useful in monitoring the response to antiangiogenic therapy in general and to VEGF inhibitor therapy. As previously noted, blood levels of bFGF and SDF1 $\alpha$ were noted to be higher in patients at the time of relapse as compared to levels observed in the response phase in patients with recurrent GBM treated with cediranib [142].

\section{Unanswered Questions}

Despite the remarkable progress in our understanding of the process of angiogenesis and the potential promise of targeting these processes for the treatment of GBM, several critical questions need to be addressed. These include questions regarding the fundamental processes involved in GBM vascularization and their role in the failure of therapy. Pressing questions in this category are: (1) are the GBM tumors in patients that have failed bevacizumab or other anti-angiogenic therapy avascular, or are the tumors coopting the existing blood vessels to obtain the oxygen and nutrients needed?, (2) is the angiopoietin signaling pathway driving a blood vessel co-option process in human GBM that have failed therapy with a VEGF inhibitor or other antiangiogenic agent?, and (3) do cancer stem cells (or glioma stem cells) promote angiogenesis in malignant gliomas and could we target them specifically with novel therapy?

There also is an urgent need to improve the ability to assess the effects of the anti-angiogenic therapies on angiogenesis (rather than tumor growth). Questions in this category include: (1) does the number of CECs and circulating EPCs in patients with tumors correlate with the tumor grade, and could their number be used to monitor anti-angiogenic therapy? (Phenotyping circulating EPCs with a comprehensive set of endothelial, progenitor, and hematopoietic markers should be performed to address the issue of what are the appropriate markers to be used to identify circulating EPCs in patients [65]), (2) what is the contribution of circulating EPCs to angiogenesis in untreated virgin tumors?, and (3) could a biomarker be identified that would aid in identifying adaptive evasive resistance (escape pathways) that should be targeted when a patient's tumor develops resistance to anti-angiogenic therapy?

\section{Conclusions}

Anti-angiogenic therapy appears to be a promising and novel approach for the treatment of malignant brain tumors. Clinical trials have shown improvement in the short-term progression-free survival. The response of patients with GBM to therapy with a VEGF inhibitor likely depends, at least in part, on whether the tumor neovasculature contains a normal density of pericytes, how capable the tumor is in co-opting pre-existing blood vessels, and whether previously co-opted blood vessels exist in the tumor. A better understanding of the mechanisms of resistance to anti-angiogenic therapy is needed such that we can improve our treatment strategies for these patients. The development and optimization of biomarkers to measure angiogenesis in tumors, such as quantitation of the numbers of CECs and circulating EPCs, will potentially help us identify patients that are responding to, or failing, anti-angiogenic therapy. Theoretically, these markers could also be used to identify the subset of patients that would benefit from anti-angiogenic 
therapy and thereby individualizing therapy for patients with malignant tumors, such as GBM. In addition, new antiangiogenic therapies that induce apoptosis of the ECs in the neovasculature are needed, as this type of anti-angiogenic therapy may be less likely to induce therapeutic resistance.

\section{Acknowledgments}

We thank Drs. Gene Barnett, Derek Raghavan, and Fiona Hunter for critical review of this manuscript. This work was supported by grants CA 109748 and CA 127620 from the National Institutes of Health-National Cancer Institute to CLG.

\section{References}

[1] P. Y. Wen and S. Kesari, "Malignant gliomas in adults," New England Journal of Medicine, vol. 359, no. 5, pp. 492-507, 2008.

[2] CBTRUS, "Primary brain tumors in the United States, 20002004," Statistical Report, Central Brain Tumor Registry of the United States, 2008.

[3] R. Stupp, W. P. Mason, M. J. van den Bent, et al., "Radiotherapy plus concomitant and adjuvant temozolomide for glioblastoma," New England Journal of Medicine, vol. 352, no. 10, pp. 987-996, 2005.

[4] T. Y. Kang, T. Jin, H. Elinzano, and D. Peereboom, "Irinotecan and bevacizumab in progressive primary brain tumors, an evaluation of efficacy and safety," Journal of NeuroOncology, vol. 89, no. 1, pp. 113-118, 2008.

[5] J. J. Vredenburgh, A. Desjardins, J. E. Herndon II, et al., "Bevacizumab plus irinotecan in recurrent glioblastoma multiforme," Journal of Clinical Oncology, vol. 25, no. 30, pp. 4722-4729, 2007.

[6] H. S. Friedman, M. D. Prados, P. Y. Wen, et al., "Bevacizumab alone and in combination with irinotecan in recurrent glioblastoma," Journal of Clinical Oncology, vol. 27, no. 28, pp. 4733-4740, 2009.

[7] P. Kleihues, D. N. Louis, B. W. Scheithauer, et al., "The WHO classification of tumors of the nervous system," Journal of Neuropathology and Experimental Neurology, vol. 61, no. 3, pp. 215-225, 2002.

[8] J. Folkman, "Antiangiogenesis in cancer therapy-endostatin and its mechanisms of action," Experimental Cell Research, vol. 312, no. 5, pp. 594-607, 2006.

[9] D. Hanahan and J. Folkman, "Patterns and emerging mechanisms of the angiogenic switch during tumorigenesis," Cell, vol. 86, no. 3, pp. 353-364, 1996.

[10] J. Holash, P. C. Maisonpierre, D. Compton, et al., "Vessel cooption, regression, and growth in tumors mediated by angiopoietins and VEGF," Science, vol. 284, no. 5422, pp. 1994-1998, 1999.

[11] F. Hillen and A. W. Griffioen, "Tumour vascularization: sprouting angiogenesis and beyond," Cancer and Metastasis Reviews, vol. 26, no. 3-4, pp. 489-502, 2007.

[12] D. R. Senger, S. J. Galli, A. M. Dvorak, C. A. Perruzzi, V. S. Harvey, and H. F. Dvorak, "Tumor cells secrete a vascular permeability factor that promotes accumulation of ascites fluid," Science, vol. 219, no. 4587, pp. 983-985, 1983.

[13] P. J. Keck, S. D. Hauser, G. Krivi, et al., "Vascular permeability factor, an endothelial cell mitogen related to PDGF," Science, vol. 246, no. 4935, pp. 1309-1312, 1989.
[14] D. W. Leung, G. Cachianes, W.-J. Kuang, D. V. Goeddel, and N. Ferrara, "Vascular endothelial growth factor is a secreted angiogenic mitogen," Science, vol. 246, no. 4935, pp. 13061309, 1989.

[15] N. Ferrara, H.-P. Gerber, and J. LeCouter, "The biology of VEGF and its receptors," Nature Medicine, vol. 9, no. 6, pp. 669-676, 2003.

[16] J. M. Whitelock, A. D. Murdoch, R. V. Iozzo, and P. A. Underwood, "The degradation of human endothelial cellderived perlecan and release of bound basic fibroblast growth factor by stromelysin, collagenase, plasmin, and heparanases," Journal of Biological Chemistry, vol. 271, no. 17, pp. 10079-10086, 1996.

[17] D. Qiao, K. Meyer, C. Mundhenke, S. A. Drew, and A. Friedl, "Heparan sulfate proteoglycans as regulators of fibroblast growth factor-2 signaling in brain endothelial cells: specific role for glypican-1 in glioma angiogenesis," Journal of Biological Chemistry, vol. 278, no. 18, pp. 16045-16053, 2003.

[18] A. N. Witmer, J. Dai, H. A. Weich, G. F. J. M. Vrensen, and R. O. Schlingemann, "Expression of vascular endothelial growth factor receptors 1, 2, and 3 in quiescent endothelia," Journal of Histochemistry and Cytochemistry, vol. 50, no. 6, pp. 767777, 2002.

[19] R. S. Morrison, F. Yamaguchi, H. Saya, et al., "Basic fibroblast growth factor and fibroblast growth factor receptor I are implicated in the growth of human astrocytomas," Journal of Neuro-Oncology, vol. 18, no. 3, pp. 207-216, 1994.

[20] R. S. Morrison, F. Yamaguchi, J. M. Bruner, M. Tang, W. McKeehan, and M. S. Berger, "Fibroblast growth factor receptor gene expression and immunoreactivity are elevated in human glioblastoma multiforme," Cancer Research, vol. 54, no. 10, pp. 2794-2799, 1994.

[21] S. M. Yamada, S. Yamada, Y. Hayashi, H. Takahashi, A. Teramoto, and K. Matsumoto, "Fibroblast growth factor receptor (FGFR) 4 correlated with the malignancy of human astrocytomas," Neurological Research, vol. 24, no. 3, pp. 244248, 2002.

[22] T. Ueba, J. A. Takahashi, M. Fukumoto, et al., "Expression of fibroblast growth factor receptor-1 in human glioma and meningioma tissues," Neurosurgery, vol. 34, no. 2, pp. 221226, 1994.

[23] M. Simons, "Integrative signaling in angiogenesis," Molecular and Cellular Biochemistry, vol. 264, no. 1-2, pp. 99-102, 2004.

[24] G. Pintucci, D. Moscatelli, F. Saponara, et al., "Lack of ERK activation and cell migration in FGF-2-deficient endothelial cells," The FASEB Journal, vol. 16, no. 6, pp. 598-600, 2002.

[25] G. Gliki, C. Wheeler-Jones, and I. Zachary, "Vascular endothelial growth factor induces protein kinase C (PKC)dependent Akt/PKB activation and phosphatidylinositol 3' kinase-mediated $\mathrm{PKC} \delta$ phosphorylation: role of PKC in angiogenesis," Cell Biology International, vol. 26, no. 9, pp. 751-759, 2002.

[26] S. Karcher, H.-H. Steiner, R. Ahmadi, et al., "Different angiogenic phenotypes in primary and secondary glioblastomas," International Journal of Cancer, vol. 118, no. 9, pp. 21822189, 2006.

[27] S. S. Lakka, C. S. Gondi, D. H. Dinh, et al., "Specific interference of urokinase-type plasminogen activator receptor and matrix metalloproteinase- 9 gene expression induced by double-stranded RNA results in decreased invasion, tumor growth, and angiogenesis in gliomas," Journal of Biological Chemistry, vol. 280, no. 23, pp. 21882-21892, 2005. 
[28] S. S. Lakka, C. S. Gondi, and J. S. Rao, "Proteases and glioma angiogenesis," Brain Pathology, vol. 15, no. 4, pp. 327-341, 2005.

[29] S. M. Pulukuri, C. S. Gondi, S. S. Lakka, et al., "RNA interference-directed knockdown of urokinase plasminogen activator and urokinase plasminogen activator receptor inhibits prostate cancer cell invasion, survival, and tumorigenicity in vivo," Journal of Biological Chemistry, vol. 280, no. 43, pp. 36529-36540, 2005.

[30] C. S. Gondi, S. S. Lakka, D. H. Dinh, W. C. Olivero, M. Gujrati, and J. S. Rao, "Intraperitoneal injection of a hairpin RNA- expressing plasmid targeting urokinasetype Plasminogen Activator (uPA) receptor and uPA retards angiogenesis and inhibits intracranial tumor growth in nude mice," Clinical Cancer Research, vol. 13, no. 14, pp. 40514060, 2007.

[31] L. Sun, A.-M. Hui, Q. Su, et al., "Neuronal and gliomaderived stem cell factor induces angiogenesis within the brain," Cancer Cell, vol. 9, no. 4, pp. 287-300, 2006.

[32] B. Wolff, A. R. Burns, J. Middleton, and A. Rot, "Endothelial cell 'memory' of inflammatory stimulation: human venular endothelial cells store interleukin 8 in Weibel-Palade bodies," Journal of Experimental Medicine, vol. 188, no. 9, pp. 17571762, 1998.

[33] J. O. Utgaard, F. L. Jahnsen, A. Bakka, P. Brandtzaeg, and G. Haraldsen, "Rapid secretion of prestored interleukin 8 from Weibel-Palade bodies of microvascular endothelial cells," Journal of Experimental Medicine, vol. 188, no. 9, pp. 17511756, 1998.

[34] D. J. Brat, A. C. Bellail, and E. G. Van Meir, "The role of interleukin-8 and its receptors in gliomagenesis and tumoral angiogenesis," Neuro-Oncology, vol. 7, no. 2, pp. 122-133, 2005.

[35] L. Eklund and B. R. Olsen, "Tie receptors and their angiopoietin ligands are context-dependent regulators of vascular remodeling," Experimental Cell Research, vol. 312, no. 5, pp. 630-641, 2006.

[36] G. Bergers and S. Song, "The role of pericytes in blood-vessel formation and maintenance," Neuro-Oncology, vol. 7, no. 4, pp. 452-464, 2005.

[37] D. Zagzag, R. Amirnovin, M. A. Greco, et al., "Vascular apoptosis and involution in gliomas precede neovascularization: a novel concept for glioma growth and angiogenesis," Laboratory Investigation, vol. 80, no. 6, pp. 837-849, 2000.

[38] C. M. Overall and O. Kleifeld, "Validating matrix metalloproteinases as drug targets and anti-targets for cancer therapy," Nature Reviews Cancer, vol. 6, no. 3, pp. 227-239, 2006.

[39] J. D. Hood, R. Frausto, W. B. Kiosses, M. A. Schwartz, and D. A. Cheresh, "Differential $\alpha \mathrm{v}$ integrin-mediated Ras-ERK signaling during two pathways of angiogenesis," Journal of Cell Biology, vol. 162, no. 5, pp. 933-943, 2003.

[40] B. Kaur, F. W. Khwaja, E. A. Severson, S. L. Matheny, D. J. Brat, and E. G. Van Meir, "Hypoxia and the hypoxiainducible-factor pathway in glioma growth and angiogenesis," Neuro-Oncology, vol. 7, no. 2, pp. 134-153, 2005.

[41] P. Baluk, S. Morikawa, A. Haskell, M. Mancuso, and D. M. McDonald, "Abnormalities of basement membrane on blood vessels and endothelial sprouts in tumors," American Journal of Pathology, vol. 163, no. 5, pp. 1801-1815, 2003.

[42] A. N. Stratman, K. M. Malotte, R. D. Mahan, M. J. Davis, and G. E. Davis, "Pericyte recruitment during vasculogenic tube assembly stimulates endothelial basement membrane matrix formation," Blood, vol. 114, no. 24, pp. 5091-5101, 2009.
[43] A. N. Stratman, W. B. Saunders, A. Sacharidou, et al., "Endothelial cell lumen and vascular guidance tunnel formation requires MT1-MMP-dependent proteolysis in 3dimensional collagen matrices," Blood, vol. 114, no. 2, pp. 237-247, 2009.

[44] G. Bergers and D. Hanahan, "Modes of resistance to antiangiogenic therapy," Nature Reviews Cancer, vol. 8, no. 8, pp. 592-603, 2008.

[45] D. J. Ceradini, A. R. Kulkarni, M. J. Callaghan, et al., "Progenitor cell trafficking is regulated by hypoxic gradients through HIF-1 induction of SDF-1," Nature Medicine, vol. 10, no. 8, pp. 858-864, 2004.

[46] S. A. Rempel, S. Dudas, S. Ge, and J. A. Gutierrez, "Identification and localization of the cytokine SDF1 and its receptor, CXC chemokine receptor 4 , to regions of necrosis and angiogenesis in human glioblastoma," Clinical Cancer Research, vol. 6, no. 1, pp. 102-111, 2000.

[47] J. B. Rubin, A. L. Kung, R. S. Klein, et al., "A small-molecule antagonist of CXCR4 inhibits intracranial growth of primary brain tumors," Proceedings of the National Academy of Sciences of the United States of America, vol. 100, no. 23, pp. 13513-13518, 2003.

[48] G. Arismendi-Morillo and A. Castellano, "Tumoral microblood vessels and vascular microenvironment in human astrocytic tumors. A transmission electron microscopy study," Journal of Neuro-Oncology, vol. 73, no. 3, pp. 211-217, 2005.

[49] Y. Boucher, M. Leunig, and R. K. Jain, "Tumor angiogenesis and interstitial hypertension," Cancer Research, vol. 56, no. 18, pp. 4264-4266, 1996.

[50] B. Kaur, F. W. Khwaja, E. A. Severson, S. L. Matheny, D. J. Brat, and E. G. Van Meir, "Hypoxia and the hypoxiainducible-factor pathway in glioma growth and angiogenesis," Neuro-Oncology, vol. 7, no. 2, pp. 134-153, 2005.

[51] Z. Li, S. Bao, Q. Wu, et al., "Hypoxia-inducible factors regulate tumorigenic capacity of glioma stem cells," Cancer Cell, vol. 15, no. 6, pp. 501-513, 2009.

[52] T. Lapidot, C. Sirard, J. Vormoor, et al., "A cell initiating human acute myeloid leukaemia after transplantation into SCID mice," Nature, vol. 367, no. 6464, pp. 645-648, 1994.

[53] B. A. Peters, L. A. Diaz Jr., K. Polyak, et al., "Contribution of bone marrow-derived endothelial cells to human tumor vasculature," Nature Medicine, vol. 11, no. 3, pp. 261-262, 2005.

[54] M. Al-Hajj, M. S. Wicha, A. Benito-Hernandez, S. J. Morrison, and M. F. Clarke, "Prospective identification of tumorigenic breast cancer cells," Proceedings of the National Academy of Sciences of the United States of America, vol. 100, no. 7, pp. 3983-3988, 2003.

[55] M. F. Clarke, J. E. Dick, P. B. Dirks, et al., "Cancer stem cellsperspectives on current status and future directions: AACR workshop on cancer stem cells," Cancer Research, vol. 66, no. 19, pp. 9339-9344, 2006.

[56] S. Bao, Q. Wu, S. Sathornsumetee, et al., "Stem cell-like glioma cells promote tumor angiogenesis through vascular endothelial growth factor," Cancer Research, vol. 66, no. 16, pp. 7843-7848, 2006.

[57] C. Calabrese, H. Poppleton, M. Kocak, et al., "A perivascular niche for brain tumor stem cells," Cancer Cell, vol. 11, no. 1, pp. 69-82, 2007.

[58] R. J. Gilbertson and J. N. Rich, "Making a tumour's bed: glioblastoma stem cells and the vascular niche," Nature Reviews Cancer, vol. 7, no. 10, pp. 733-736, 2007. 
[59] C. Folkins, Y. Shaked, S. Man, et al., "Glioma tumor stemlike cells promote tumor angiogenesis and vasculogenesis via vascular endothelial growth factor and stromal-derived factor 1," Cancer Research, vol. 69, no. 18, pp. 7243-7251, 2009.

[60] H.-G. Kopp, C. A. Ramos, and S. Rafii, "Contribution of endothelial progenitors and proangiogenic hematopoietic cells to vascularization of tumor and ischemic tissue," Current Opinion in Hematology, vol. 13, no. 3, pp. 175-181, 2006.

[61] P. Carmeliet, "Angiogenesis in life, disease and medicine," Nature, vol. 438, no. 7070, pp. 932-936, 2005.

[62] T. Asahara, T. Murohara, A. Sullivan, et al., "Isolation of putative progenitor endothelial cells for angiogenesis," Science, vol. 275, no. 5302, pp. 964-967, 1997.

[63] Y. Shaked, A. Ciarrocchi, M. Franco, et al., "Therapy-induced acute recruitment of circulating endothelial progenitor cells to tumors," Science, vol. 313, no. 5794, pp. 1785-1787, 2006.

[64] D. G. Duda, K. S. Cohen, S. V. Kozin, et al., "Evidence for incorporation of bone marrow-derived endothelial cells into perfused blood vessels in tumors," Blood, vol. 107, no. 7, pp. 2774-2776, 2006.

[65] F. Bertolini, Y. Shaked, P. Mancuso, and R. S. Kerbel, “The multifaceted circulating endothelial cell in cancer: towards marker and target identification," Nature Reviews Cancer, vol. 6, no. 11, pp. 835-845, 2006.

[66] R. S. Kerbel, R. Benezra, D. C. Lyden, et al., "Endothelial progenitor cells are cellular hubs essential for neoangiogenesis of certain aggressive adenocarcinomas and metastatic transition but not adenomas," Proceedings of the National Academy of Sciences of the United States of America, vol. 105, no. 34, p. E54, 2008.

[67] H. Spring, T. Schuler, B. Arnold, G. J. Hämmerling, and R. Ganss, "Chemokines direct endothelial progenitors into tumor neovessels," Proceedings of the National Academy of Sciences of the United States of America, vol. 102, no. 50, pp. 18111-18116, 2005.

[68] N. Rafat, G. C. Beck, J. Schulte, J. Tuettenbeg, and P. Vajkoczy, "Circulating endothelial progenitor cells in malignant gliomas," Journal of Neurosurgery, vol. 112, no. 1, pp. 43-49, 2010.

[69] L. Yang, J. Huang, X. Ren, et al., "Abrogation of TGF $\beta$ signaling in mammary carcinomas recruits Gr- $1+\mathrm{CD} 11 \mathrm{~b}+$ myeloid cells that promote metastasis," Cancer Cell, vol. 13, no. 1, pp. 23-35, 2008.

[70] J. W. Pollard, "Tumour-educated macrophages promote tumour progression and metastasis," Nature Reviews Cancer, vol. 4, no. 1, pp. 71-78, 2004.

[71] M. De Palma, M. A. Venneri, R. Galli, et al., "Tie2 identifies a hematopoietic lineage of proangiogenic monocytes required for tumor vessel formation and a mesenchymal population of pericyte progenitors," Cancer Cell, vol. 8, no. 3, pp. 211-226, 2005.

[72] D. K. Jin, K. Shido, H.-G. Kopp, et al., "Cytokine-mediated deployment of SDF-1 induces revascularization through recruitment of CXCR4+ hemangiocytes," Nature Medicine, vol. 12, no. 5, pp. 557-567, 2006.

[73] M. Grunewald, I. Avraham, Y. Dor, et al., "VEGF-induced adult neovascularization: recruitment, retention, and role of accessory cells," Cell, vol. 124, no. 1, pp. 175-189, 2006.

[74] S. Song, A. J. Ewald, W. Stallcup, Z. Werb, and G. Bergers, "PDGFR $\beta^{+}$perivascular progenitor cells in tumours regulate pericyte differentiation and vascular survival," Nature Cell Biology, vol. 7, no. 9, pp. 870-879, 2005.
[75] J. R. Conejo-Garcia, R. J. Buckanovich, F. Benencia, et al., "Vascular leukocytes contribute to tumor vascularization," Blood, vol. 105, no. 2, pp. 679-681, 2005.

[76] F. Shojaei and N. Ferrara, "Refractoriness to antivascular endothelial growth factor treatment: role of myeloid cells," Cancer Research, vol. 68, no. 14, pp. 5501-5504, 2008.

[77] J. J. Vredenburgh, A. Desjardins, J. E. Herndon II, et al., "Phase II trial of bevacizumab and irinotecan in recurrent malignant glioma," Clinical Cancer Research, vol. 13, no. 4, pp. 1253-1259, 2007.

[78] E. T. Wong, K. R. Hess, M. J. Gleason, et al., "Outcomes and prognostic factors in recurrent glioma patients enrolled onto phase II clinical trials," Journal of Clinical Oncology, vol. 17, no. 8, pp. 2572-2578, 1999.

[79] W. K. A. Yung, M. D. Prados, R. Yaya-Tur, et al., "Multicenter phase II trial of temozolomide in patients with anaplastic astrocytoma or anaplastic oligoastrocytoma at first relapse," Journal of Clinical Oncology, vol. 17, no. 9, pp. 2762-2771, 1999.

[80] W. K.A. Yung, R. E. Albright, J. Olson, et al., "A phase II study of temozolemide vs. procarbazine in patients with glioblastoma multiforme at first relapse," British Journal of Cancer, vol. 83, no. 5, pp. 588-593, 2000.

[81] W. Chen, S. Delaloye, D. H. S. Silverman, et al., "Predicting treatment response of malignant gliomas to bevacizumab and irinotecan by imaging proliferation with $\left[{ }^{18} \mathrm{~F}\right]$ fluorothymidine positron emission tomography: a pilot study," Journal of Clinical Oncology, vol. 25, no. 30, pp. 4714-4721, 2007.

[82] A. D. Norden, G. S. Young, K. Setayesh, et al., "Bevacizumab for recurrent malignant gliomas: efficacy, toxicity, and patterns of recurrence," Neurology, vol. 70, no. 10, pp. 779-787, 2008.

[83] S. Guiu, S. Taillibert, O. Chinot, et al., "Bevacizumab/ Irinotecan. An active treatment for recurrent high grade gliomas: preliminary results of an ANOCEF Multicenter Study," Revue Neurologique, vol. 164, no. 6-7, pp. 588-594, 2008.

[84] T. N. Kreisl, L. Kim, K. Moore, et al., "Phase II trial of singleagent bevacizumab followed by bevacizumab plus irinotecan at tumor progression in recurrent glioblastoma," Journal of Clinical Oncology, vol. 27, no. 5, pp. 740-745, 2009.

[85] http://www.rtog.org/members/protocols/0825/0825.pdf.

[86] http://clinicaltrials.gov/ct2/show/NCT00943826?term=bevacizumab+temozolomide+glioma\&rank $=17$.

[87] J. Holash, S. Davis, N. Papadopoulos, et al., "VEGF-Trap: a VEGF blocker with potent antitumor effects," Proceedings of the National Academy of Sciences of the United States of America, vol. 99, no. 17, pp. 11393-11398, 2002.

[88] J. Holash, S. Davis, N. Papadopoulos, et al., "VEGF-Trap: a VEGF blocker with potent antitumor effects," Proceedings of the National Academy of Sciences of the United States of America, vol. 99, no. 17, pp. 11393-11398, 2002.

[89] J. F. De Groot, P. Y. Wen, K. Lamborn, et al., "Phase II single arm trial of aflibercept in patients with recurrent temozolomide-resistant glioblastoma: NABTC 0601," Journal of Clinical Oncology, vol. 26, p. 2020, 2008.

[90] T. T. Batchelor, A. G. Sorensen, E. di Tomaso, et al., "AZD2171, a pan-VEGF receptor tyrosine kinase inhibitor, normalizes tumor vasculature and alleviates edema in glioblastoma patients," Cancer Cell, vol. 11, no. 1, pp. 83-95, 2007. 
[91] C. Conrad, H. Friedman, D. Reardon, et al., “A phase I/II trial of single-agent PTK 787/ZK 222584 (PTK/ZK), a novel, oral angiogenesis inhibitor, in patients with recurrent glioblastoma multiforme (GBM)," Journal of Clinical Oncology, vol. 22, p. 1512, 2004.

[92] J. F. De Groot, M. Prados, and T. Urquhart, "A phase II study of XL184 in patients (pts) with progressive glioblastoma multiforme (GBM) in first or second relapse," Journal of Clinical Oncology, vol. 27, no. 15S, p. 2047, 2009.

[93] H. A. Fine, W. D. Figg, K. Jaeckle, et al., "Phase II trial of the antiangiogenic agent thalidomide in patients with recurrent high-grade gliomas," Journal of Clinical Oncology, vol. 18, no. 4, pp. 708-715, 2000.

[94] D. A. Reardon, K. L. Fink, T. Mikkelsen, et al., "Randomized phase II study of cilengitide, an integrin-targeting arginineglycine-aspartic acid peptide, in recurrent glioblastoma multiforme," Journal of Clinical Oncology, vol. 26, no. 34, pp. 5610-5617, 2008.

[95] T. Kilic, J. A. Alberta, P. R. Zdunek, et al., "Intracranial inhibition of platelet-derived growth factor-mediated glioblastoma cell growth by an orally active kinase inhibitor of the 2phenylaminopyrimidine class," Cancer Research, vol. 60, no. 18, pp. 5143-5150, 2000.

[96] P. Y. Wen, W. K. A. Yung, K. R. Lamborn, et al., "Phase I/II study of imatinib mesylate for recurrent malignant gliomas: north American Brain Tumor Consortium Study 99-08," Clinical Cancer Research, vol. 12, no. 16, pp. 4899-4907, 2006.

[97] A. Desjardins, J. A. Quinn, J. J. Vredenburgh, et al., "Phase II study of imatinib mesylate and hydroxyurea for recurrent grade III malignant gliomas," Journal of Neuro-Oncology, vol. 83, no. 1, pp. 53-60, 2007.

[98] D. A. Reardon, M. J. Egorin, J. A. Quinn, et al., "Phase II study of imatinib mesylate plus hydroxyurea in adults with recurrent glioblastoma multiforme," Journal of Clinical Oncology, vol. 23, no. 36, pp. 9359-9368, 2005.

[99] D. A. Reardon, A. Desjardins, J. J. Vredenburgh, et al., "Safety and pharmacokinetics of dose-intensive imatinib mesylate plus temozolomide: phase 1 trial in adults with malignant glioma," Neuro-Oncology, vol. 10, no. 3, pp. 330-340, 2008.

[100] B. J. Scott, E. C. Quant, M. B. McNamara, P. A. Ryg, T. T. Batchelor, P. Y. Wen, "Bevacizumab salvage therapy following progression in high-grade glioma patients treated with VEGF receptor tyrosine kinase inhibitors," Neuro-Oncology [Epub ahead of print], 2010.

[101] E. P. Jane, D. R. Premkumar, and I. F. Pollack, "Coadministration of sorafenib with rottlerin potently inhibits cell proliferation and migration in human malignant glioma cells," Journal of Pharmacology and Experimental Therapeutics, vol. 319, no. 3, pp. 1070-1080, 2006.

[102] C. Yu, B. B. Friday, J.-P. Lai, et al., "Cytotoxic synergy between the multikinase inhibitor sorafenib and the proteasome inhibitor bortezomib in vitro: induction of apoptosis through Akt and c-Jun $\mathrm{NH}_{2}$-terminal kinase pathways," Molecular Cancer Therapeutics, vol. 5, no. 9, pp. 2378-2387, 2006.

[103] Q. Zhou and J. M. Gallo, "Differential effect of sunitinib on the distribution of temozolomide in an orthotopic glioma model," Neuro-Oncology, vol. 11, no. 3, pp. 301-310, 2009.

[104] S. Sathornsumetee and J. N. Rich, "Vandetanib, a novel multitargeted kinase inhibitor, in cancer therapy," Drugs of Today, vol. 42, no. 10, pp. 657-670, 2006.
[105] J. N. Rich, D. Loncar, S. Sathornsumetee, et al., "ZD6474, a vascular endothelial growth factor receptor 2 (VEGFR2) inhibitor, inhibits growth of multiple primary central nervous system tumor types," p. 413.

[106] J. N. Rich, S. Sathornsumetee, S. T. Keir, et al., "ZD6474, a novel tyrosine kinase inhibitor of vascular endothelial growth factor receptor and epidermal growth factor receptor, inhibits tumor growth of multiple nervous system tumors," Clinical Cancer Research, vol. 11, no. 22, pp. 8145-8157, 2005.

[107] V. Damiano, D. Melisi, C. Bianco, et al., "Cooperative antitumor effect of multitargeted kinase inhibitor ZD6474 and ionizing radiation in glioblastoma," Clinical Cancer Research, vol. 11, no. 15, pp. 5639-5644, 2005.

[108] L. M. Jost, H.-P. Gschwind, T. Jalava, et al., "Metabolism and disposition of vatalanib (PTK787/ZK-222584) in cancer patients," Drug Metabolism and Disposition, vol. 34, no. 11, pp. 1817-1828, 2006.

[109] M. P. Saunders, R. Wilson, M. Peeters, et al., "Vandetanib with FOLFIRI in patients with advanced colorectal adenocarcinoma: results from an open-label, multicentre Phase i study," Cancer Chemotherapy and Pharmacology, vol. 64, no. 4, pp. 665-672, 2009.

[110] E. N. Scott, G. Meinhardt, C. Jacques, D. Laurent, and A. L. Thomas, "Vatalanib: the clinical development of a tyrosine kinase inhibitor of angiogenesis in solid tumours," Expert Opinion on Investigational Drugs, vol. 16, no. 3, pp. 367-379, 2007.

[111] A. L. Thomas, B. Morgan, M. A. Horsfield, et al., "Phase I study of the safety, tolerability, pharmacokinetics, and pharmacodynamics of PTK787/ZK 222584 administered twice daily in patients with advanced cancer," Journal of Clinical Oncology, vol. 23, no. 18, pp. 4162-4171, 2005.

[112] D. Reardon, H. Friedman, N. Brada, et al., "A phase I/II trial of PTK787/ZK 222584 (PTK/ZK), a multi-VEGF receptor tyrosine kinase inhibitor, in combination with either temozolomide or lomustine for patients with recurrent glioblastoma multiforme (GBM)," Neuro-Oncology, vol. 6, p. 381, 2004.

[113] J. P. Kirkpatrick, J. N. Rich, J. J. Vredenburgh, et al., "Final report: phase I trial of imatinib mesylate, hydroxyurea, and vatalanib for patients with recurrent malignant glioma (MG)," Journal of Clinical Oncology, vol. 26, no. 15S, p. 2057, 2008.

[114] D. A. Reardon, M. J. Egorin, A. Desjardins, et al., "Phase I pharmacokinetic study of the vascular endothelial growth factor receptor tyrosine kinase inhibitor vatalanib (PTK787) plus imatinib and hydroxyurea for malignant glioma," Cancer, vol. 115, no. 10, pp. 2188-2198, 2009.

[115] R. Kurzrock, L. Camacho, D. Hong, et al., "A phase I doseescalation study of the safety and pharmacokinetics of a XL184, a VEGFR and Met kinase inhibitor, administered orally to subjects with advanced malignancies," European Journal of Cancer, vol. 4, p. 405, 2006.

[116] R. Salgia, D. Hong, S. I. Sherman, et al., "A phase 1 doseescalation study of the safety and pharmacokinetics (PK) of XL184, a VEGFR and MET kinase inhibitor, administered orally to patients (pts) with advanced malignancies," Molecular Cancer Therapeutics, vol. 6, p. 3385S, 2007.

[117] R. Abounader and J. Laterra, "Scatter factor/hepatocyte growth factor in brain tumor growth and angiogenesis," Neuro-Oncology, vol. 7, no. 4, pp. 436-451, 2005.

[118] R. J. D’Amato, M. S. Loughnan, E. Flynn, and J. Folkman, "Thalidomide is an inhibitor of angiogenesis," Proceedings 
of the National Academy of Sciences of the United States of America, vol. 91, no. 9, pp. 4082-4085, 1994.

[119] S. C. Short, D. Traish, A. Dowe, F. Hines, M. Gore, and M. Brada, "Thalidomide as an anti-angiogenic agent in relapsed gliomas," Journal of Neuro-Oncology, vol. 51, no. 1, pp. 41-45, 2001.

[120] H. A. Fine, P. Y. Wen, E. A. Maher, et al., "Phase II trial of thalidomide and carmustine for patients with recurrent highgrade gliomas," Journal of Clinical Oncology, vol. 21, no. 12, pp. 2299-2304, 2003.

[121] G. M. Marx, N. Pavlakis, S. McCowatt, et al., "Phase II study of Thalidomide in the treatment of recurrent glioblastoma multiforme," Journal of Neuro-Oncology, vol. 54, no. 1, pp. 31-38, 2001.

[122] V. K. Puduvalli, P. Giglio, M. D. Groves, et al., "Phase II trial of irinotecan and thalidomide in adults with recurrent glioblastoma multiforme," Neuro-Oncology, vol. 10, no. 2, pp. 216-222, 2008.

[123] F. Baumann, M. Bjeljac, S. S. Kollias, et al., "Combined thalidomide and temozolomide treatment in patients with glioblastoma multiforme," Journal of Neuro-Oncology, vol. 67, no. 1-2, pp. 191-200, 2004.

[124] H. A. Fine, L. Kim, P. S. Albert, et al., "A phase I trial of lenalidomide in patients with recurrent primary central nervous system tumors," Clinical Cancer Research, vol. 13, no. 23, pp. 7101-7106, 2007.

[125] J. Drappatz, E. T. Wong, D. Schiff, et al., "A pilot safety study of lenalidomide and radiotherapy for patients with newly diagnosed glioblastoma multiforme," International Journal of Radiation Oncology Biology Physics, vol. 73, no. 1, pp. 222227, 2009.

[126] A. B. Da Rocha, D. R. A. Mans, A. Regner, and G. Schwartsmann, "Targeting protein kinase C: new therapeutic opportunities against high-grade malignant gliomas?" Oncologist, vol. 7, no. 1, pp. 17-33, 2002.

[127] A. A. Brandes, M. Ermani, S. Turazzi, et al., "Procarbazine and high-dose tamoxifen as a second-line regimen in recurrent high-grade gliomas: a phase II study," Journal of Clinical Oncology, vol. 17, no. 2, pp. 645-650, 1999.

[128] A. M. Spence, R. A. Peterson, J. D. Scharnhorst, D. L. Silbergeld, and R. C. Rostomily, "Phase II study of concurrent continuous temozolomide (TMZ) and tamoxifen (TMX) for recurrent malignant astrocytic gliomas," Journal of NeuroOncology, vol. 70, no. 1, pp. 91-95, 2004.

[129] M. C. Chamberlain and P. A. Kormanik, "Salvage chemotherapy with tamoxifen for recurrent anaplastic astrocytomas," Archives of Neurology, vol. 56, no. 6, pp. 703-708, 1999.

[130] H. A. Fine, V. K. Puduvalli, M. C. Chamberlain, et al., "Enzastaurin (ENZ) versus lomustine (CCNU) in the treatment of recurrent, intracranial glioblastoma multiforme (GBM): a phase III study," Journal of Clinical Oncology, vol. 26, no. 25S, abstract 2005, 2008.

[131] J. R. Graff, A. M. McNulty, K. R. Hanna, et al., “The protein kinase $\mathrm{C} \beta$-selective inhibitor, Enzastaurin (LY317615.HCl), suppresses signaling through the AKT pathway, induces apoptosis, and suppresses growth of human colon cancer and glioblastoma xenografts," Cancer Research, vol. 65, no. 16, pp. 7462-7469, 2005.

[132] C. J. Avraamides, B. Garmy-Susini, and J. A. Varner, "Integrins in angiogenesis and lymphangiogenesis," Nature Reviews Cancer, vol. 8, no. 8, pp. 604-617, 2008.
[133] R. Stupp, R. Goldbrunner, and B. Neyns, "Mature results of a phase I/IIA trial of the integrin inhibitor cilengitide (EMD121974) added to standard concomitant and adjuvant temozolomide and radiotherapy (TMZ/RT) for newly diagnosed glioblastoma (GBM)," in Proceedings of the 12th Annual Meeting of the Society for Neuro-Oncology, 2007.

[134] D. R. Macdonald, T. L. Cascino, S. C. Schold Jr., and J. G. Cairncross, "Response criteria for phase II studies of supratentorial malignant glioma," Journal of Clinical Oncology, vol. 8, no. 7, pp. 1277-1280, 1990.

[135] T. T. Batchelor, D.G. Duda, and E. di Tomaso, "Normalization of tumor vasculature and alleviation of edema by AZD2171, a pan-VEGF receptor tyrosine kinase inhibitor in glioblastoma patients," International Journal of Radiation, vol. 69, no. 3, supplement 1, pp. S50-S51, 2007.

[136] M. J. van den Bent, M. A. Vogelbaum, P. Y. Wen, D. R. Macdonald, and S. M. Chang, "End point assessment in gliomas: novel treatments limit usefulness of classical Macdonald's criteria," Journal of Clinical Oncology, vol. 27, no. 18, pp. 2905-2908, 2009.

[137] E. C. Quant, A. D. Norden, J. Drappatz, et al., "Role of a second chemotherapy in recurrent malignant glioma patients who progress on bevacizumab," Neuro-Oncology, vol. 11, no. 5, pp. 550-555, 2009.

[138] M. Paez-Ribes, E. Allen, J. Hudock, et al., "Antiangiogenic therapy elicits malignant progression of tumors to increased local invasion and distant metastasis," Cancer Cell, vol. 15, no. 3, pp. 220-231, 2009.

[139] J. M. L. Ebos, C. R. Lee, W. Cruz-Munoz, G. A. Bjarnason, J. G. Christensen, and R. S. Kerbel, "Accelerated metastasis after short-term treatment with a potent inhibitor of tumor angiogenesis," Cancer Cell, vol. 15, no. 3, pp. 232-239, 2009.

[140] G. Bergers and D. Hanahan, "Modes of resistance to antiangiogenic therapy," Nature Reviews Cancer, vol. 8, no. 8, pp. 592-603, 2008.

[141] L. Ellis and D. J. Hicklin, "Pathways mediating resistance to vascular endothelial growth factor-targeted therapy," Clinical Cancer Research, vol. 14, no. 20, pp. 6371-6375, 2008.

[142] R. Abounader and J. Laterra, "Scatter factor/hepatocyte growth factor in brain tumor growth and angiogenesis," Neuro-Oncology, vol. 7, no. 4, pp. 436-451, 2005.

[143] I. Petit, D. Jin, and S. Rafii, "The SDF-1-CXCR4 signaling pathway: a molecular hub modulating neo-angiogenesis," Trends in Immunology, vol. 28, no. 7, pp. 299-307, 2007.

[144] E. De Falco, D. Porcelli, A. R. Torella, et al., "SDF-1 involvement in endothelial phenotype and ischemia-induced recruitment of bone marrow progenitor cells," Blood, vol. 104, no. 12, pp. 3472-3482, 2004.

[145] M. Aghi, K. S. Cohen, R. J. Klein, D. T. Scadden, and E. A. Chiocca, "Tumor stromal-derived factor-1 recruits vascular progenitors to mitotic neovasculature, where microenvironment influences their differentiated phenotypes," Cancer Research, vol. 66, no. 18, pp. 9054-9064, 2006.

[146] R. Du, K. V. Lu, C. Petritsch, et al., "HIF1 $\alpha$ induces the recruitment of bone marrow-derived vascular modulatory cells to regulate tumor angiogenesis and invasion," Cancer Cell, vol. 13, no. 3, pp. 206-220, 2008.

[147] G. Bergers, S. Song, N. Meyer-Morse, E. Bergsland, and D. Hanahan, "Benefits of targeting both pericytes and endothelial cells in the tumor vasculature with kinase inhibitors," Journal of Clinical Investigation, vol. 111, no. 9, pp. 12871295, 2003. 
[148] S. Song, A. J. Ewald, W. Stallcup, Z. Werb, and G. Bergers, "PDGFR $\beta^{+}$perivascular progenitor cells in tumours regulate pericyte differentiation and vascular survival," Nature Cell Biology, vol. 7, no. 9, pp. 870-879, 2005.

[149] D. C. Darland, L. J. Massingham, S. R. Smith, E. Piek, M. Saint-Geniez, and P. A. D'Amore, "Pericyte production of cell-associated VEGF is differentiation-dependent and is associated with endothelial survival," Developmental Biology, vol. 264, no. 1, pp. 275-288, 2003.

[150] P. Kunkel, U. Ulbricht, P. Bohlen, et al., "Inhibition of glioma angiogenesis and growth in vivo by systemic treatment with a monoclonal antibody against vascular endothelial growth factor receptor-2," Cancer Research, vol. 61, no. 18, pp. 6624$6628,2001$.

[151] J. L. Rubenstein, J. Kim, T. Ozawa, et al., "Anti-VEGF antibody treatment of glioblastoma prolongs survival but results in increased vascular cooption," Neoplasia, vol. 2, no. 4, pp. 306-314, 2000.

[152] L. L. Muldoon, C. Soussain, K. Jahnke, et al., "Chemotherapy delivery issues in central nervous system malignancy: a reality check," Journal of Clinical Oncology, vol. 25, no. 16, pp. 22952305, 2007.

[153] C. Calatozzolo, M. Gelati, E. Ciusani, et al., "Expression of drug resistance proteins Pgp, MRP1, MRP3, MRP5 AND GST- $\pi$ in human glioma," Journal of Neuro-Oncology, vol. 74, no. 2, pp. 113-121, 2005.

[154] N. Giri, N. Shaik, G. Pan, et al., "Investigation of the role of breast cancer resistance protein (Bcrp/Abcg2) on pharmacokinetics and central nervous system penetration of abacavir and zidovudine in the mouse," Drug Metabolism and Disposition, vol. 36, no. 8, pp. 1476-1484, 2008.

[155] H. Dai, P. Marbach, M. Lemaire, M. Hayes, and W. F. Elmquist, "Distribution of STI-571 to the brain is limited by P-glycoprotein-mediated efflux," Journal of Pharmacology and Experimental Therapeutics, vol. 304, no. 3, pp. 10851092, 2003.

[156] L. A. Doyle and D. D. Ross, "Multidrug resistance mediated by the breast cancer resistance protein BCRP (ABCG2)," Oncogene, vol. 22, no. 47, pp. 7340-7358, 2003.

[157] R. K. Jain, D. G. Duda, C. G. Willett, et al., "Biomarkers of response and resistance to antiangiogenic therapy," Nature Reviews Clinical Oncology, vol. 6, no. 6, pp. 327-338, 2009.

[158] L. G. Daenen, Y. Shaked, S. Man, et al., "Low-dose metronomic cyclophosphamide combined with vascular disrupting therapy induces potent antitumor activity in preclinical human tumor xenograft models," Molecular Cancer Therapeutics, vol. 8, no. 10, pp. 2872-2881, 2009.

[159] A. M. Jubb, H. I. Hurwitz, W. Bai, et al., "Impact of vascular endothelial growth factor-A expression, thrombospondin-2 expression, and microvessel density on the treatment effect of bevacizumab in metastatic colorectal cancer," Journal of Clinical Oncology, vol. 24, no. 2, pp. 217-227, 2006.

[160] A. Dowlati, R. Gray, A. B. Sandler, J. H. Schiller, and D. H. Johnson, "Cell adhesion molecules, vascular endothelial growth factor, and basic fibroblast growth factor in patients with non-small cell lung cancer treated with chemotherapy with or without bevacizumab-an Eastern Cooperative Oncology Group study," Clinical Cancer Research, vol. 14, no. 5, pp. 1407-1412, 2008.

[161] H. J. Burstein, Y.-H. Chen, L. M. Parker, et al., "VEGF as a marker for outcome among advanced breast cancer patients receiving anti-VEGF therapy with bevacizumab and vinorelbine chemotherapy," Clinical Cancer Research, vol. 14, no. 23, pp. 7871-7877, 2008. 


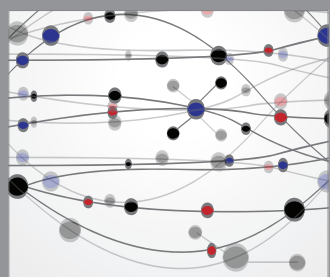

The Scientific World Journal
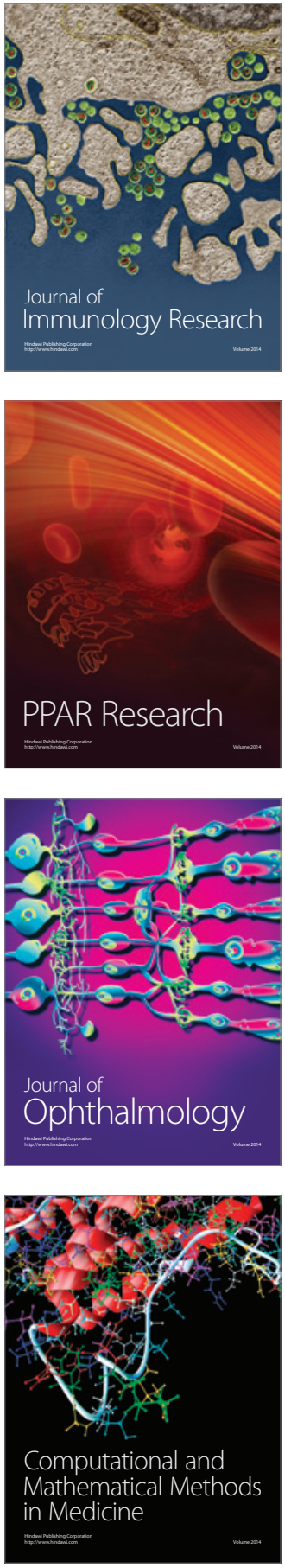

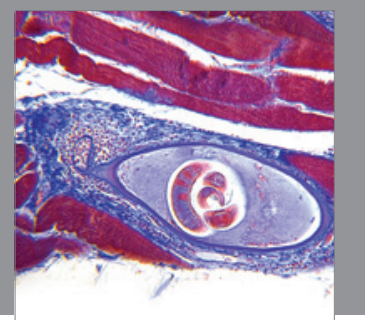

Gastroenterology

Research and Practice
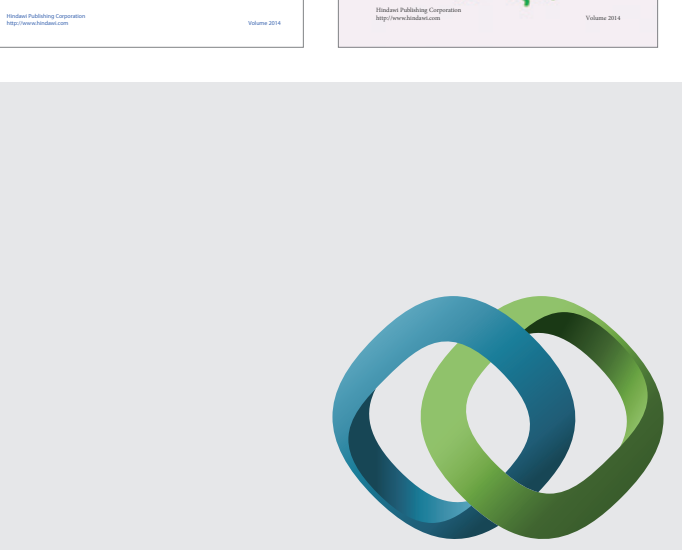

\section{Hindawi}

Submit your manuscripts at

http://www.hindawi.com
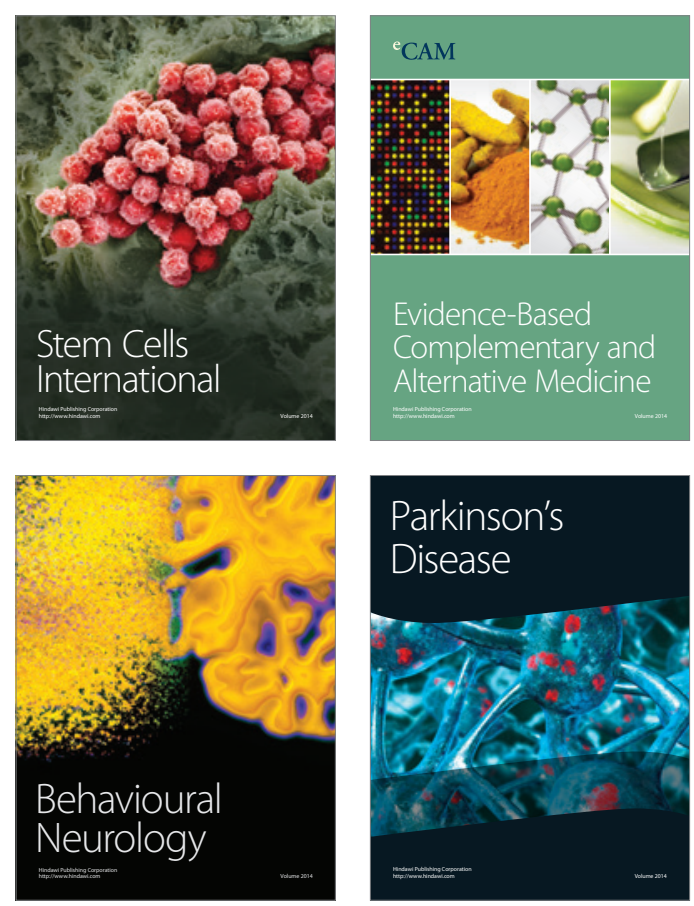

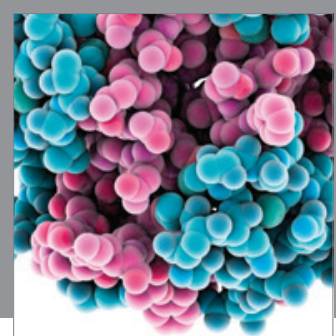

Journal of
Diabetes Research

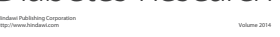

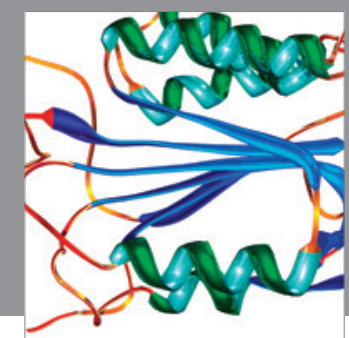

Disease Markers
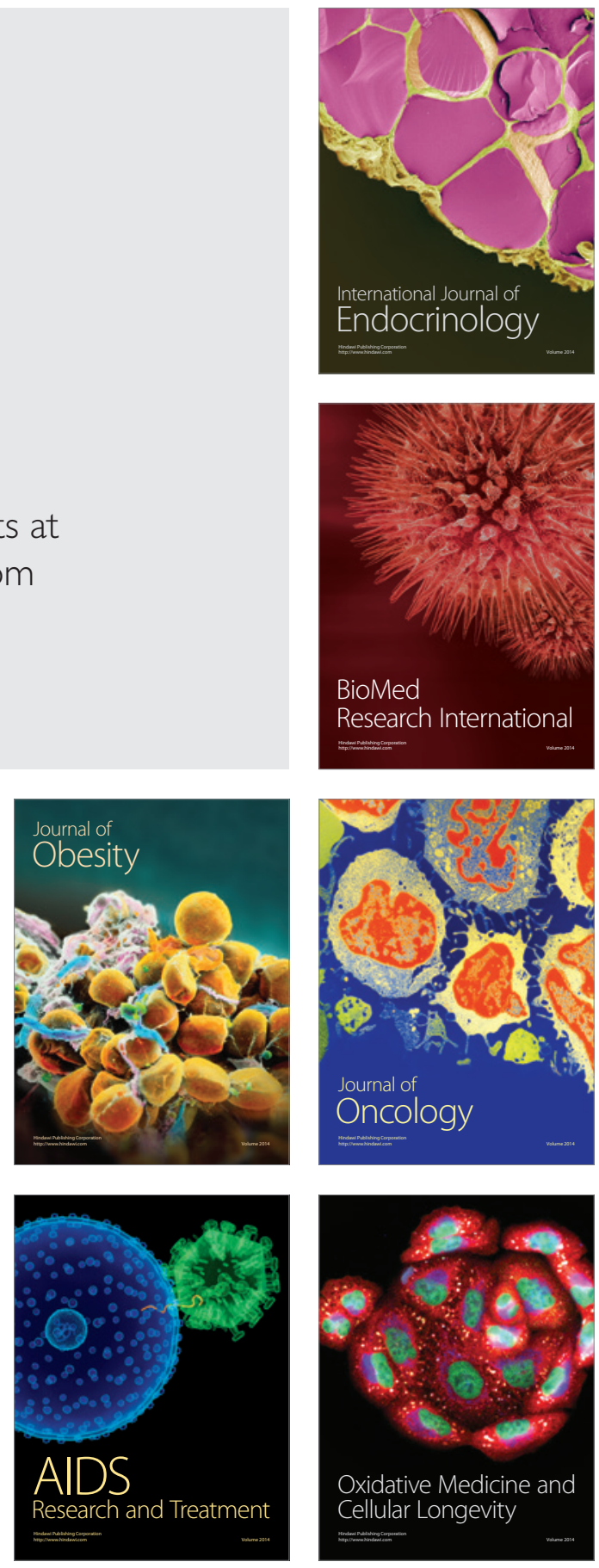